\title{
Reduced kinase D-interacting substrate of 220 kDa (Kidins220) in pancreatic cancer promotes EGFR/ERK signalling and disease progression
}

\author{
SHUO CAI ${ }^{1,2}$, ZHIWEI SUN $^{1,3}$, PING-HUI SUN ${ }^{1}$, XIANGYU GAO ${ }^{1,4,5}$, KE JI ${ }^{1,4,5}$, XIUYUN TIAN ${ }^{5}$, \\ JIAFU JI ${ }^{4}$, CHUNYI HAO ${ }^{5}$, FARIS SOLIMAN ${ }^{1}$, CHANG LIU ${ }^{1}$, BILAL AL-SARIREH ${ }^{6}$, \\ PAUL GRIFFITHS ${ }^{7}$, STEPHEN HISCOX $^{8}$, WEN G. JIANG ${ }^{1}$ and LIN YE ${ }^{1}$
}

\begin{abstract}
${ }^{1}$ Cardiff China Medical Research Collaborative, Division of Cancer and Genetics, Cardiff University School of Medicine, Cardiff CF14 4XN, UK; ${ }^{2}$ Department of Endoscopy Center, and ${ }^{3}$ VIP-II Division of Medical Department,

Key Laboratory of Carcinogenesis and Translational Research (Ministry of Education, Beijing),

Peking University Cancer Hospital and Institute; ${ }^{4}$ Gastrointestinal Tumour Centre, Key Laboratory of Carcinogenesis and Translational Research (Ministry of Education, Beijing), Peking University Cancer Hospital and Institute;

${ }^{5}$ Department of Hepato-Pancreato-Biliary Surgery, Key Laboratory of Carcinogenesis and Translational Research (Ministry of Education, Beijing), Peking University Cancer Hospital and Institute, Beijing 100142, P.R. China; Departments of ${ }^{6}$ Surgery, and ${ }^{7}$ Pathology, Morriston Hospital, ABM University Health Board, Swansea SA6 6NL;

${ }^{8}$ School of Pharmacy and Pharmaceutical Sciences, Cardiff University, Redwood Building,
\end{abstract}

King Edward VII Avenue, Cardiff CF10 3NB, UK

Received January 20, 2021; Accepted April 13, 2021

DOI: $10.3892 /$ ijo.2021.5214

\begin{abstract}
Kidins 220 is a transmembrane scaffold protein involved in several types of cancer. The aim of the present study was to examine the role of Kidins 220 in tumorigenesis and disease progression of pancreatic cancer. The relevant signalling pathways including EGFR, EMT, and MMP were also investigated. The expression of Kidins220 was examined at the transcript and protein level. The Kidins 220 knockdown cell model was established and its influence on cellular functions was determined. Involvement of Kidins 220 in tumorigenesis and metastasis was examined in CD1 mice, respectively. The results showed that, reduced Kidin 220 expression was associated with tumorigenesis, metastasis, and overall survival of pancreatic cancer. Knockdown of Kidins220 promoted proliferation, colony formation and tumorigenic capacity of pancreatic cancer cells in vitro and in vivo, respectively. Kidins 220 regulated pancreatic cancer cell migration through the EGFR/AKT/ERK signalling pathway. Furthermore, enhanced EMT was observed in the pancreatic cancer cell lines with the knockdown of Kidins220,
\end{abstract}

Correspondence to: Dr Lin Ye, Cardiff China Medical Research Collaborative, Division of Cancer and Genetics, Cardiff University School of Medicine, Academic Avenue, Cardiff CF14 4XN, UK E-mail: yel@cardiff.ac.uk

Key words: Kidins220, pancreatic cancer, metastasis, epidermal growth factor receptor, invasion and matrix metalloproteinase underlying EGFR regulation. Kidins220 also affected cell invasion via MMP1. A reduced expression of Kidins 220 was observed in pancreatic cancer, which is associated with disease progression, distant metastasis and poor prognosis. The loss of Kidins 220 in pancreatic cancer may contribute to disease progression through the upregulation of EGFR and downstream signalling.

\section{Introduction}

Kidins220 (kinase D-interacting substrate of $220 \mathrm{kDa}$ ) is a novel scaffolding protein with an important role acting as the downstream substrate of Trks, which are neurotrophin receptors (1). Kidins220 regulates neuronal differentiation, survival, and cytoskeleton remodeling, by interacting with a variety of binding partners (2). Kidins220 is a transmembrane protein with 1715 amino acids. It elicits its function as a platform by binding/interacting with different molecules through the function domain/motifs at either $\mathrm{N}$ - or C-terminals as both terminals face intracellularly. It has 11 ankyrin-repeats at the $\mathrm{N}$-terminal, while the C-terminal comprises PSD-95, Dlg, ZO-1 (PDZ)-binding motif, kinase light chain interacting motif (KIM), a sterile $\alpha$ motif (SAM) and a proline-rich domain. There are juxta membrane Walker A/B motifs located at both terminals (3). Kidins220 acts as a platform to coordinate signal transduction, cytoskeleton arrangement, molecule transport and cellular functions via these intracellular domains at both $\mathrm{N}$ - and C-terminals (3). In addition to this, it has been implicated in malignancies. For example, Kidins 220 contributes to melanoma progression by sustained MAPK signalling and inhibiting stress-induced apoptosis (4). 
In neuroblastoma, Kidins220 stabilizes NGF-induced survival signaling and is associated with morphological transition of cells from N- to S-type (5). Moreover, Kidins220 is a direct target gene of miR-4638-5p, a microRNA with decreased expression in castration-resistant prostate cancer (CRPC). Previous findings indicated that miR-4638-5p, through regulating Kidins220 and the downstream activity of VEGF and PI3K/AKT signalling pathways, influences prostate cancer progression via angiogenesis (6).

At present, the role played by Kidins 220 in pancreatic cancer and other intestinal malignancies remains unknown. Our preliminary investigation of Kidins 220 revealed an altered expression of Kidins 220 in pancreatic cancer which provoked the current study of Kidins 220 in that cancer type. The aim of the present study was to examine the involvement of Kidins 220 in the disease progression of pancreatic cancer and how it affects cellular functions of pancreatic cancer cells and corresponding molecular mechanisms.

\section{Materials and methods}

Cell lines and cell culture. PANC-1 (RRID:CVCL_0480) and MIA PaCa-2 (RRID:CVCL_0428) cancer cell lines (ATCC) were cultured in Dulbecco's modified Eagle's medium/nutrient F-12 Ham (DMEM-F12; Sigma-Aldrich, UK) with 10\% FBS and antibiotics. Cells were treated with rhEGF $(200 \mathrm{ng} / \mathrm{ml})$, gefitinib (ZD1839; Selleck Chem), ERK inhibitor (GDC-0994; Selleck Chem), AKT inhibitor (MK-2206; Selleck Chem), MMP2 (cat. no. 2621; Tocris Bioscience), and MMPs broad spectrum inhibitor (Marimastat, cat. no. 2631; Tocris Bioscience). The cell lines used in the study were mycoplasma-free and they were authenticated using STR profiling.

Generation of Kidins220 lentivirus shRNA transgenes. Lentiviral shRNA (GGCCTGCAAGATCCAATTATA) targeting Kidins220 was obtained from Cyagen Biosciences. After amplification and purification, plasmids containing lentiviral shRNA or scramble shRNA (CCTAAGGTTAAG TCGCCCTCG), together with lentiviral packaging plasmids (psPAX2) and envelope plasmid (pMD2.G) were transfected into 293 cells respectively, to generate lentiviral particles. The lentiviral particles carrying either Kidins220 shRNA or scramble shRNA were then used to infect target cells, respectively. The scramble shRNA was employed as a control for the subsequent experiments. The stable PANC-1 and MIA PaCa-2 sublines and corresponding scramble control cells were maintained in DMEM medium and supplemented with $100 \mu \mathrm{g} / \mathrm{ml} \mathrm{G} 418$.

Immunohistochemistry for pancreatic tissue microarray. Immunohistochemical staining was conducted on a pancreatic adenocarcinoma tissue microarray (TMA) comprising 10 normal pancreatic tissues derived from autopsy, 21 adjacent normal pancreatic tissues, 11 pancreatic inflammation, 10 benign tumors (pancreatic islet cell tumour), 52 malignant tumors (42 pancreatic duct adenocarcinoma, 3 pancreatic adenosquamous carcinoma, 1 pancreatic islet cell carcinoma and 6 pancreatic metastatic carcinoma) (PA2081a, Biomax). The primary antibody used was an anti-Kidins 220 rabbit monoclonal antibody (SC-48738) at 1:50 concentration
(Santa Cruz Biotechnology, UK). The secondary antibody solution consisted of $100 \mu \mathrm{l}$ biotinylated antibody stock at $5 \mathrm{ml}$ dilution (Vectastain Universal Elite ABC Kit, PK-6200, Vector Laboratories). The presence of cancerous cells was verified by a pathologist. Assessment of the staining was performed by determining the intensity of Kidins 220 staining using ImageJ (https://imagej.nih.gov/ij/). Briefly, the IHC intensity was determined in 10-20 cancerous cells by a subtraction of background of empty area on the slide for each core on the TMA. Average intensity was calculated for each sample from the duplicate cores of each sample, followed by statistical analyses.

Collection of clinical cohort. Clinical cohort includes pancreatic tumors $(n=149)$ together with paired adjacent background tissues $(n=145)$, collected immediately after surgery over a period from February, 2002 to August, 2012. Samples were stored at $-80^{\circ} \mathrm{C}$ until use. Informed consent was signed by the patients at Peking University Cancer Hospital. All protocol and procedures were approved by the Peking University Cancer Hospital Research Ethics Committee. TNM staging was evaluated by pathologists and clinicians according to the 7th edition of TNM Classification of Malignant Tumours from the International Union Against Cancer (UICC) (7).

RNA extraction cDNA synthesis and RT-PCR. Total RNA was isolated from 1-3 million cancer cells or pancreatic tissues (300-500 mg) using TRIzol Reagent ${ }^{\circledR}$ (Sigma-Aldrich), and first-strand cDNA was then produced using the GoScript ${ }^{\mathrm{TM}}$ Reverse Transcription System kit. The concentration and purity of the resulting single-stranded RNA was quantified by measuring its absorbance at a wavelength of $260 \mathrm{~nm}$ using a UV 1101 Biotech spectrophotometer (WPA). Reverse transcription was performed to convert $500 \mathrm{ng}$ of RNA into cDNA using the GoScript ${ }^{\mathrm{TM}}$ Reverse Transcription System kit (Promega Corporation). PCR was performed in PCR reaction mix with initial denaturation at $94^{\circ} \mathrm{C}$ for $5 \mathrm{~min}$, followed by $30-35$ cycles of amplification at $95^{\circ} \mathrm{C}$ for $30 \mathrm{sec}, 55^{\circ} \mathrm{C}$ for $30 \mathrm{sec}$ and $72^{\circ} \mathrm{C}$ for $30 \mathrm{sec}$, with a final extension at $72^{\circ} \mathrm{C}$ for $5 \mathrm{~min}$, while $G A P D H$ was determined as a house-keeping control.

Quantitative polymerase chain reaction ( $q P C R)$. $\mathrm{qPCR}$ for Kidins220, EGFR, NF- $\mathrm{B}$ and GAPDH was performed using the Ampliflour ${ }^{\mathrm{TM}}$ system (Intergen Company ${ }^{\circledR}$ ) with the following thermocycling conditions: $94^{\circ} \mathrm{C}$ for $10 \mathrm{~min}$, 90 cycles of $94^{\circ} \mathrm{C}$ for $10 \mathrm{sec}, 55^{\circ} \mathrm{C}$ for $35 \mathrm{sec}$, and $72^{\circ} \mathrm{C}$ for $20 \mathrm{sec}$. MMP1 transcripts and a housekeeping gene $(G A P D H)$ were determined using the SYBR-Green system and change of MMP1 in folds was calculated using the $2^{-\Delta \Delta C t}$ method (8). The primers used for qPCR are listed in Table SI.

Western blot analysis. Proteins were extracted using lysis buffer and then quantified using the Bio-Rad DC Protein Assay kit (Bio-Rad Laboratories, UK). Proteins were transferred onto PVDF membranes after a separation in the 8 or $10 \%$ SDS-PAGE gel depending on the molecular weight of target proteins, and subsequently blocked and probed with primary antibody and a corresponding peroxidise-conjugated secondary antibody. Antibody against actin (Santa Cruz Biotechnology; sc-47778), Kidins220 (Santa Cruz Biotechnology; sc-48738), 
AKT (Santa Cruz Biotechnology, sc-5298), P-AKT1,2,3 (Santa Cruz, sc-81433), ERK (Santa Cruz Biotechnology, sc-514302), P-ERK (Santa Cruz Biotechnology, sc-7383), EGFR (Santa Cruz Biotechnology, sc-71034), p-Tyr antibody (PY99; Santa Cruz Biotechnology, sc-7020), E-cadherin (Santa Cruz Biotechnology, sc-1500), Snail (Santa Cruz Biotechnology, sc-166476), and MMP1 (Santa Cruz Biotechnology, sc-21731) were purchased from Santa Cruz Biotechnology. The Snail (Abcam, ab167609) and NF- $\kappa B$ (Abcam, ab16502) PCNA (Santa Cruz Biotechnology, sc-25280) antibodies were purchased from Abcam (Cambridge, UK). The nuclear proteins were prepared using a nuclear isolation buffer $(1.58 \mathrm{M}$ sucrose, $40 \mathrm{mM}$ Tris- $\mathrm{HCl} \mathrm{pH} 7.5,20 \mathrm{mM} \mathrm{MgCl}$, $4 \%$ Triton X-100). The protein bands were eventually visualised using a chemiluminescence detection kit (Luminata). The process of immunoprecipitation involves cell lysis, followed by incubation with a specific antibody against target protein or proteins (PY99, an antibody targeting proteins with phosphorylated tyrosine) presenting within the tested protein samples. The resultant antigen-antibody complexes are then precipitated using agarose beads conjugated with staphylococcal protein A and protein $\mathrm{G}$ followed by SDS-PAGE ( 8 or 10\%) and probing with antibodies.

In vitro cell growth assay. Cells $(3,000)$ were seeded into $200 \mu 1$ medium in three 96-well plates, and cultured at $37^{\circ} \mathrm{C}$ for 1,3 and 5 days, respectively. Following incubation, the cells were fixed and stained with crystal violet. The absorbance was measured after dissolving the crystal violet with acetic acid $(10 \% \mathrm{v} / \mathrm{v})$ and the absorbance was determined at a wavelength of $540 \mathrm{~nm}$ using a spectrophotometer (Bio-Tek, Elx800).

In vitro tumor spheroid assay. Then, 1,000 cells were seeded into $200 \mu \mathrm{l}$ DMEM medium into 96-well non-coated U-shape bottom 3D culture plate (Greiner Bio-One, Ltd.). The cells were cultured at $37^{\circ} \mathrm{C}$ for a period up to 14 days. Images were captured every three days to monitor tumor growth. Culture medium was topped up every two or three days. Size of the spheroids was measured using ImageJ software.

Colony formation assay. One hundred cells were plated into 6-well plates and cultured for 14 days to allow colonies to form. Colonies were fixed with $4 \%$ formaldehyde and stained with crystal violet. The colony numbers were counted.

In vitro cell invasion assay. Transwell inserts (Greiner Bio-One Ltd.) with an $8.0 \mu \mathrm{m}$ pore size were coated with $50 \mu \mathrm{g}$ Matrigel and placed into a 24-well plate. After air drying and rehydration for the coating with Matrigel, 20,000 cells were seeded and incubated for $72 \mathrm{~h}$ at $37^{\circ} \mathrm{C}$. Cells that had invaded through the matrix and attached to the bottom side of the insert were fixed with $4 \%$ formalin and stained with $1 \%$ crystal violet at room temperature for $15 \mathrm{~min}$. The invaded cells were measured by reading the absorbance.

In vitro Transwell migration assay. A total of 20,000 cells were seeded into Transwell inserts (pore size, $8 \mu \mathrm{m}$ ) in a 24-well plate. After 24-h incubation, the cells that had migrated through and moved onto the other side of the insert were fixed with $4 \%$ formaldehyde and stained with $1 \%$ crystal violet at room temperature for $15 \mathrm{~min}$. The migrated cells were then measured by reading the absorbance.

In vitro cell migration assay (wound healing assay). $\mathrm{EVOS}^{\circledR}$ FL Auto Imaging System (Life Technologies) equipped with EVOS $^{\circledast}$ Onstage Incubator (Life Technologies) were used for the in vitro cell migration assay. Cells in $1 \mathrm{ml}$ of normal medium were pre-seeded with an appropriate density $(400,000$ cells/well) in a $24-w e l l$ plate and incubated until the formation of a monolayer on the next day. The cell monolayer was wounded with a $200 \mu \mathrm{l}$ pipette tip. Closure of the wound was monitored for $16 \mathrm{~h}$, and images were captured at the same positions of the wound.

In vivo subcutaneous xenograft mouse model. Athymic nude mice (CD1, female, 3-5 weeks, 18-22 g) were purchased from Charles River Laboratories (Charles River Laboratories International, Inc.). The mice were kept in sterile cages equipped with filter, at $24^{\circ} \mathrm{C}$ with a humidity of $50 \%$. Sterilised food and water were provided. After the mice were settled for a week in the designated laboratory, PANC-1 scramble and Kidins 220 knockdown cells were subcutaneously injected into the nude mice at a total of 5 million cells in Matrigel $(2.5 \mathrm{mg} / \mathrm{ml}$ in PBS), two inoculations per mouse and six mice per group. The mice were terminated after an inhalation of $\mathrm{CO}_{2}$ with a flow rate of $20 \%$ chamber volume displaced per minute and tumors were removed 4 weeks after the inoculation. Volume of the tumors was calculated using the formula: Tumor volume $\left(\mathrm{mm}^{3}\right)=0.5 \mathrm{x}$ width ${ }^{2} \mathrm{x}$ length. The xenograft experimental procedures and maintenance were performed in accordance with the Animals Act 1986 (Scientific procedures) and approved by the UK Home Office (PPL PE9445FC2). This xenograft model experiment and the following peritoneal metastatic experiment were conducted over a period from 20 March to 30 April, 2018.

In vivo peritoneal metastasis assay. Female $\mathrm{CD} 1$ mice, aged 3-5 weeks (18-22 g) were purchased from Charles River Laboratories. The mice were kept under the routine conditions. PANC-1 scramble and Kidins 220 knockdown cells were injected into the peritoneal cavity of the mouse with 3 million cells in $100 \mu \mathrm{l}$ of PBS per mouse. Mice were carefully monitored twice a week by measuring body weight. Peritoneal metastasis was examined after 4 weeks monitoring. The mice were terminated with $\mathrm{CO}_{2}$ inhalation. Metastatic nodules were photographed using a stereo-microscrope (Olympus) and the volume of metastatic tumors were calculated using the formula: Tumor volume $\left(\mathrm{mm}^{3}\right)=0.5 \mathrm{x}$ width ${ }^{2} \mathrm{x}$ length. The peritoneal metastatic model and maintenance of the mice were carried out by complying with the regulations of the Animals Act 1986 (Scientific procedures) under the same project licence (PPL PE9445FC2) approved by the UK Home Office.

Statistical analysis. Data were analysed as mean \pm SEM. Following a normality check, unpaired two sample t-test was employed for normally distributed data while non-normally distributed data was analysed using a Mann-Whitney test. One-way ANOVA (Bonferroni t-test) was employed for statistical analysis of multiple groups. Differences were considered statistically significant when $\mathrm{P}<0.05$. Correlation between the 
predicted miRNAs and Kidins 220 in the TCGA PAAD cohort was determined using Spearman test. Kaplan-Meier survival analysis with log rank pairwise comparison and Spearman correlation tests were carried out using SPSS software (SPSS Standard version 13.0; SPSS, Inc.).

\section{Results}

Reduced expression of Kidins 220 in pancreatic cancer and the clinical relevance. The expression of Kidins 220 in pancreatic cancer was first evaluated by determining the transcript levels of Kidins 220 in a clinical cohort comprising pancreatic tumors $(n=149)$ and the paired adjacent normal pancreatic tissues $(n=145)$ using qPCR. Clinical and pathological information together with average Kidins 220 transcript levels are shown in the Table SII. Kidins 220 transcript was significantly reduced in pancreatic tumors in comparison with adjacent normal tissues $(\mathrm{P}<0.05)$ (Fig. 1A). To examine the protein expression of Kidins220, immunohistochemical staining was performed on a pancreatic adenocarcinoma tissue microarray. Cytoplasmic staining of Kidins220 was seen in both positive control (gastric cancer tissue) and pancreatic epithelial cells in both normal and adjacent normal tissues. Malignant tumours exhibited weaker staining of Kidins 220 in comparison with adjacent normal pancreatic tissues $(\mathrm{P}<0.001)$ and normal pancreas $(\mathrm{P}<0.01)$ (Fig. 1B and D). Regarding patient prognosis, Kaplan-Meier analysis of a separate clinical cohort from a publicly available microarray database (GSE71729) showed that low expression of Kidins220 in primary pancreatic tumors was associated with poorer overall survival (Fig. 1C).

Kidins220 and tumorigenesis of pancreatic cancer. In order to examine how Kidins 220 may be involved in pancreatic tumorigenesis, a comparative analysis of Kidins 220 expression in benign lesions, non-invasive cancerous lesions, and invasive adenocarcinomas was performed, using gene expression array data (GDS3836) (9). This included normal pancreatic tissues $(n=7)$, intraductal papillary-mucinous adenoma (IPMA, $\mathrm{n}=6$ ), intraductal papillary-mucinous carcinoma (IPMC, $n=6$ ) and invasive cancer originating in intraductal papillary-mucinous neoplasm (IPMN, $n=3$ ). As shown in Fig. 2A, a trend of reduced expression of Kidins 220 was observed in lesions which occurred during the tumorigenesis of pancreatic cancer from IPMA, IPMC, and invasive cancer originating in IPMN compared with normal pancreas. A decreased Kidins220 expression was observed in the invasive cancers compared with normal pancreatic tissues $(\mathrm{P}<0.001)$ and IPMC $(\mathrm{P}<0.01)$. Furthermore, the semi-quantification of Kidins220 IHC staining on the TMA showed that malignant tumors had the lowest expression of Kidins220 compared with normal pancreas, pancreas with hyperplasia, and benign tumors (Fig. 2B). In order to investigate the role of Kidins 220 in regulating cellular function, knockdown of Kidins 220 using lentiviral Kidins 220 shRNA was conducted in PANC-1 and MIA PaCa-2 pancreatic cancer cell lines. The knockdown of Kidins 220 in both cell lines was then verified using both RT-PCR and western blot analysis (Fig. 2C). De-regulated and uncontrolled cell proliferation is an important trait of cancer cells. The impact of Kidins 220 knockdown on the proliferation of these two pancreatic cell lines was first evaluated using the in vitro growth assay. The knockdown of Kidins220 resulted in an increasing proliferation in the two cell lines but to variable levels. A marginal increase of proliferation was observed in the PANC-1 cells following the knockdown of Kidins 220 at Day 5 compared with the scramble control $(\mathrm{P}<0.05)$. Similarly, in the MIA PaCa- 2 cells, the cells with Kidins 220 knockdown exhibited an increase of cell proliferation compared to control (Fig. 2D). We also performed colony formation assay and found that knockdown of Kidins 220 promoted the colony formation in both PANC-1 and MIA PaCa-2 cell lines (Fig. 2E). In the 3D spheroid model, tumor spheroids formed by PANC-1 ${ }^{\text {Kidins220sh }}$ cells with knockdown of kidins 220 presented bigger spheroids compared with the scramble control cells (PANC-1 ${ }^{\text {scramble }}$ ) at the fourth day. At the final stage, the spheroids formed by Kidins220 knockdown cells became irregular in comparison with the scramble cells (days 10-13). In a similar manner, the single and suspended MIA PaCa- 2 cancer cells started to assemble themselves and form cell aggregates (day 1). The difference of spheroid solidity was observed from Day 4. MIA PaCa-2 $2^{\text {Kidins220sh }}$ cells also presented bigger spheroids in comparison with the scramble control. From Day 7, the spheroids became circular in the Kidins 220 knockdown cells. At the end of the 2-week experiment, the Kidins220 knockdown MIA PaCa-2 cells grew into much larger spheroids compared with the scramble control $(\mathrm{P}<0.001)$ (Fig. 2F). Tumorigenic capacity of the cells was also determined using a murine xenograft model. As shown in Fig. 2G, knockdown of Kidins 220 promoted tumour growth of Pancl cells in vivo (Fig. 2G).

Kidins220 and disease progression of pancreatic cancer. More advanced tumours with lymph node and/or distant metastases (which includes stages TNM3 and TNM4) $(n=19)$, exhibited lower transcript levels of Kidins220 compared with early stage tumors (TNM1 and TNM2) $(\mathrm{n}=114)(\mathrm{P}<0.01)$ (Fig. 3A). It indicates a connection between reduced expression of Kidins 220 and distant metastasis. After a search of gene expression array databases, a dataset comprising primary tumours $(n=146)$ and distant metastases $(n=62)$ was chosen for a corresponding analysis. The distant metastasis showed a decreased expression of Kidins220 compared with the primary tumors $(\mathrm{P}<0.05)$ (GSE71729) (Fig. 3B). The IHC analysis revealed that primary tumors with distant metastasis exhibited a lower expression of Kidins220 protein compared to those without metastasis. Since only two primary tumors with distant metastasis were available on the TMA, statistical comparison did not show a significant connection (data not shown). No obvious difference was identified in the Kidins 220 staining in the pancreatic metastatic samples from liver, peritoneum, omentum and lymph node (data not shown) which may be due to the limited number of samples available on the TMA.

Knockdown of kidins220 resulted in a marked increase of invasiveness in both PANC-1 and MIA PaCa-2 cells in comparison with the controls (Fig. 3C). Transwell migration assay showed that there was significantly enhanced cell migration in PANC-1 and MIA PaCa-2 pancreatic cancer cells as a result of the Kidins220 knockdown (Fig. 3D). This result was also in accordance with a measurement of cell migration using wound (scratch) assay in PANC-1 and MIA PaCa-2 cells using the wound healing assay. Cell migration was monitored over 
A

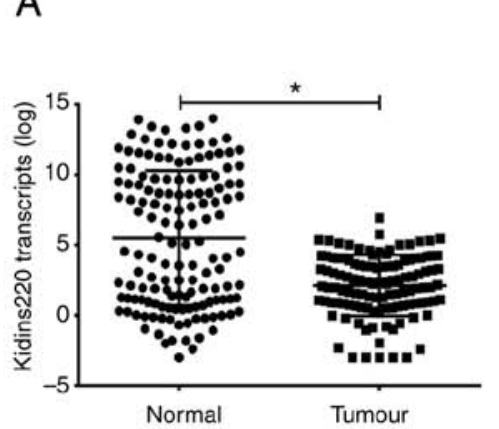

B

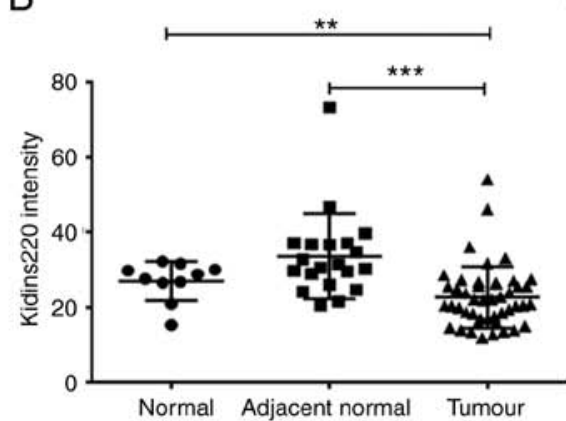

C

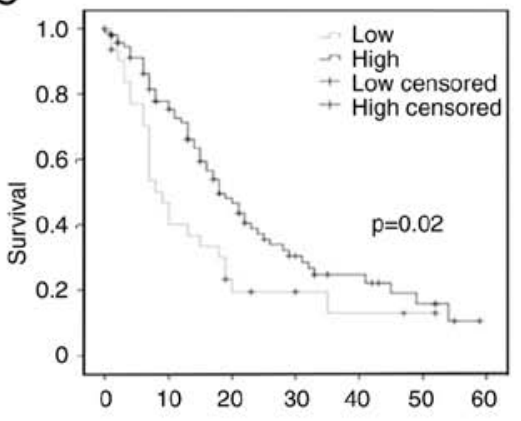

D
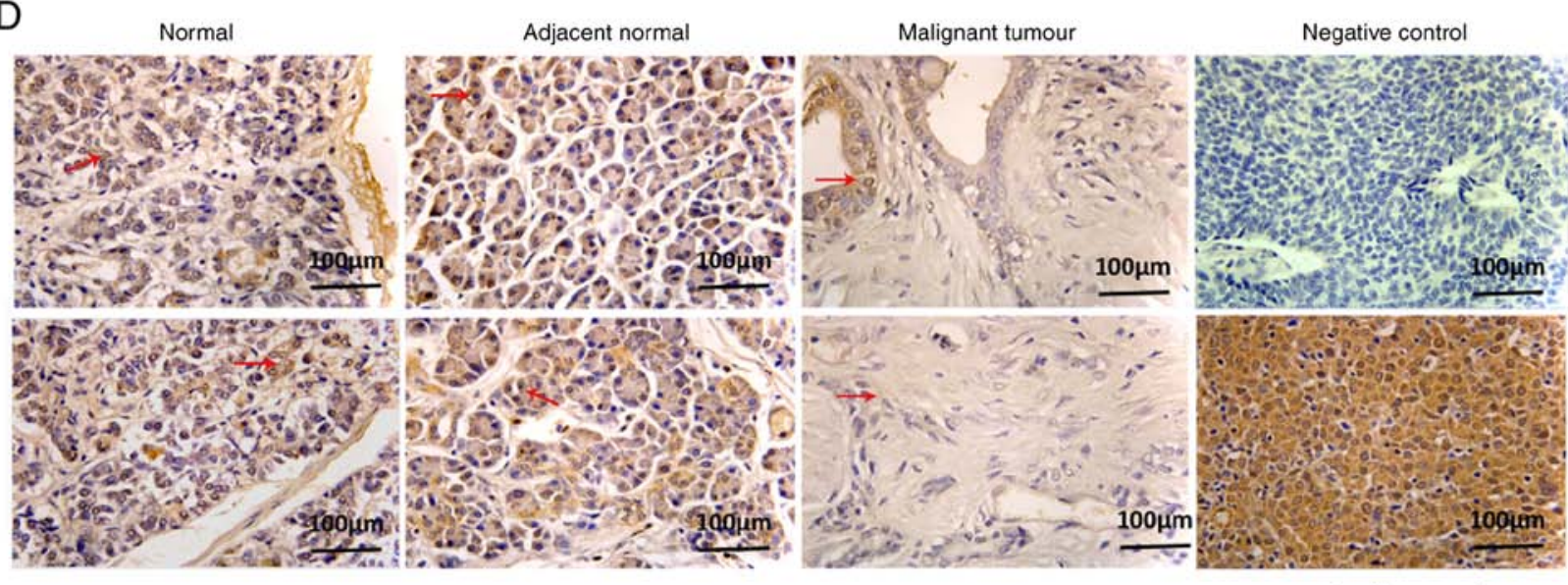

Positive control

Figure 1. Downregulated Kidins220 in pancreatic cancer is associated with poor prognosis. (A) Kidins220 transcripts were reduced in pancreatic tumour tissues compared with the adjacent normal tissues in clinical cancer cohort ( $\mathrm{P}<0.05)$. Shown are average transcript levels of Kidins 220 per 50 ng RNA and error bars represent standard error of mean. (B) The expression of Kidins 220 protein was assessed in a pancreatic tissue microarray (TMA PA2081a) with IHC staining (pancreatic tumour versus adjacent normal control, ${ }^{* * * *} \mathrm{P}<0.001$; pancreatic tumour versus normal tissue,${ }^{* *} \mathrm{P}<0.01$ ). Shown are semi-quantification of the staining intensity. (C) Correlation between Kidins220 expression (mRNA) and overall survival of patients with pancreatic cancer was analysed in the gene expression array data (GSE71729) using Kaplan-Meier survival analysis. (D) Shown are representative images of IHC staining of the TMA: 2 each of normal pancreatic tissues; adjacent pancreatic tissues; malignant tumour tissues; negative control and positive control. The negative control is an endogenous peroxidase $\mathrm{H}_{2} \mathrm{O}_{2}$, and the positive control is Kidins 220 in gastric cancer. Images were captured at $x 400$ magnification.

a period of $16 \mathrm{~h}$ following the wounding. It was shown that PANC-1 and MIA PaCa-2 cells with knockdown of Kidins 220 migrated faster compared with the scramble control cells (Fig. 3E). Furthermore, PANC-1 pancreatic cancer cells (scramble and shKidins220) were injected into the peritoneal cavity of 6 athymic nude mice in each group. The mice were terminated after 4 weeks and intraperitoneal exploration was conducted to detect the metastatic tumors in the liver, stomach, pancreas, and duodenum to rectum. Interestingly, tumor burden of the mice injected with Kidins 220 knockdown PANC-1 cells was significantly increased in comparison with scramble control (Fig. 3F). Furthermore, there is a significant increase in average tumor volume in the mice injected with PANC-1 $1^{\text {Kidins220sh }}$ cells compared with the control group.

Kidins220 regulates invasion of pancreatic cancer cells through MMP1. Our in vitro and in vivo experimental data have shown that the knockdown of Kidins220 leads to a more aggressive and invasive trait in pancreatic cell lines. Matrix metalloproteinases (MMPs) are known for their role in modulating the tumor microenvironment and enabling enhanced tumor cell invasion. An analysis was performed for the expression profile of MMPs in pancreatic cancer using publically available gene expression data (GSE71729). MMP1, MMP7,
MMP9, MMP11 and MMP17 are expressed at relatively higher levels than other MMPs in normal pancreas which are further upregulated in primary tumors (Fig. 4A). The expression pattern of MMPs appears to be similar from adjacent normal to primary tumors and metastases. Spearman's correlation test revealed an inverse correlation existing between Kidins220 and MMP1 (Fig. 4B). Subsequent quantification of MMP1 transcripts in the Kidins 220 knockdown cell lines showed an increased expression of MMP1 (Fig. 4C). Increased protein expression of MMP1 was also identified in these cells following the knockdown of Kidins220 (Fig. 4D). Targeting MMPs using small inhibitors, no obvious impact on the invasiveness was observed when the cell lines were treated with an MMP2 inhibitor. However, the other MMP inhibitor with a concentration of $5 \mathrm{nM}$ being specific to MMP1, reduced the Kidins 220 knockdown-promoted invasion in MIA PaCa-2 cells and to a lesser extent also in the PANC-1 cells (Fig. 4E and F).

Knockdown of Kidins 220 promoted cell migration through upregulation of EGFR/ERK/AKT signaling. An increased protein level of EGFR was seen in both PANC-1 and MIA PaCa-2 cancer cell lines following the knockdown of Kidins220 without notable change of EGFR mRNA in those cell lines (Fig. 5A and B). Increased p-EGFR (Tyr) was also observed 

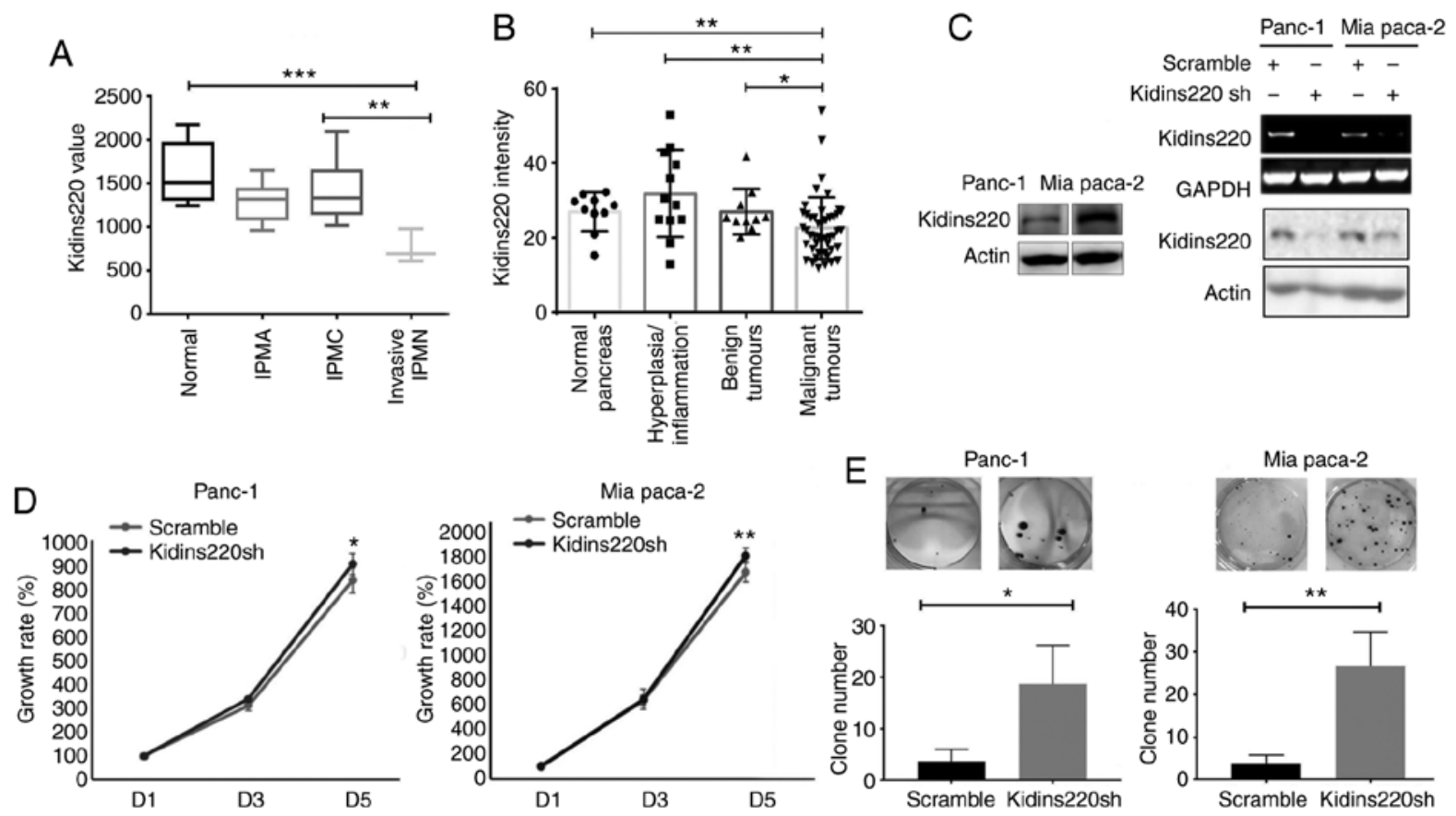

E

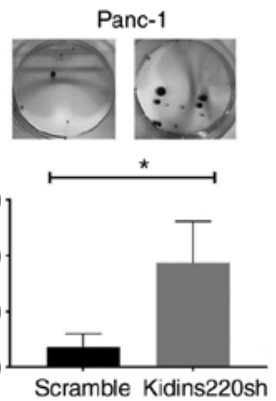

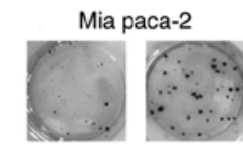

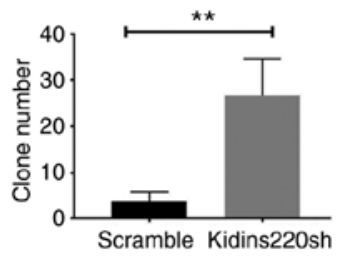

$\mathrm{F}$
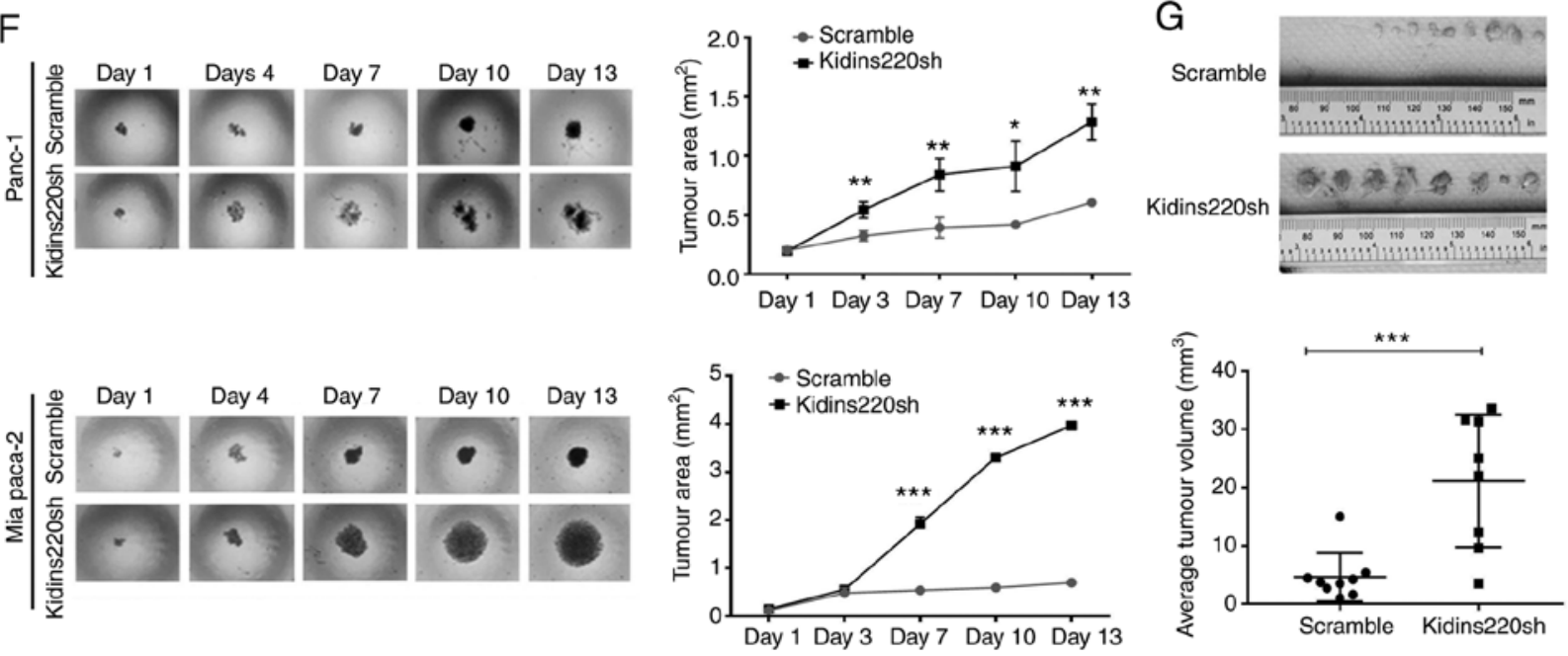

Figure 2. Effect of Kidins220 in tumorigenesis and proliferation of pancreatic cancer. (A) The expression of Kidins220 in different lesions during development of pancreatic cancer. (B) Kidins220 expression in malignant tumors compared to other different pancreatic lesions and normal pancreas. Shown are the intensity of Kidins220 IHC staining on the TMA (PA2081a, Biomax). (C) Knockdown of Kidins220 in PANC-1 and MIA PaCa-2 pancreatic cancer cells infected with Kidins220 lentiviral shRNA particles was verified at both mRNA and protein levels. (D) The impact of Kidins220 on cell growth was determined using an in vitro cell growth assay for PANC-1 and MIA PaCa-2 pancreatic cancer cell lines. Three repeats were included for each cell lines on each plate. Growth rate (\%) was calculated using the formula: Growth rate (\%)=Absorbance (Day X)/Absorbance (Day 1) x100. Shown are representative results of one experiment out of three performed. Error bars represent standard deviation. (E) The influence of Kidins220 in colony formation of PANC-1 and MIA PaCa-2 cell lines. (F) The growth of Kidins220 knockdown in PANC-1 and MIA PaCa-2 cells was examined using a 3D spheroid model. A total of 1,000 PANC-1 cells were seeded in the 96-well U-bottom plates. Representative images of PANC-1 spheroids were captured using the EVOS Auto imaging system at the indicated time over a period of two weeks. Spheroid size was measured using Image $\mathbf{J}$ software. Each cell line was tested in triplicate. Three experiments were performed. Shown are representative images and results. Error bars are standard deviations. ${ }^{* * *} \mathrm{P}<0.001,{ }^{* * *} \mathrm{P}<0.01,{ }^{*} \mathrm{P}<0.05$. (G) Knockdown of Kidins 220 facilitated tumor growth in vivo. PANC-1 scramble and Kidins 220 knockdown cells were subcutaneously injected in CD1 mice, two inoculations per mouse and six mice per group. Photograph of xenograft tumours and average tumour volume were presented.

in the Kidins 220 knockdown cells in comparison with the scramble controls, suggesting that knockdown of Kidins220 affected EGFR protein level and signalling. Corresponding activation of downstream ERK and AKT were seen in both PANC-1 and MIA PaCa-2 Kidins220 knockdown cell lines. Elevated expression and activation of EGFR and ERK was observed in the cells exposed to recombinant human EGF (Fig. 5C) with further enhanced phosphorylation of EGFR and ERK seen in the PANC-1 $1^{\text {kidins220sh }}$ cells compared to scramble control. The involvement of the enhanced EGFR/ERK signalling was further evaluated using small inhibitors targeting these molecules. Blockage of EGFR using gefitinib reduced the Kindins220 knockdown-promoted migration in both PANC-1 and MIA PaCa-2 cells. A esimilar effect was observed in the cells when they were treated with small inhibitors targeting ERK and AKT (Fig. 5D and E). More interestingly, a further analysis showed an inverse correlation between Kidins 220 mRNA levels and EGFR protein expression in the pancreatic tumors (Fig. 5F). 
A
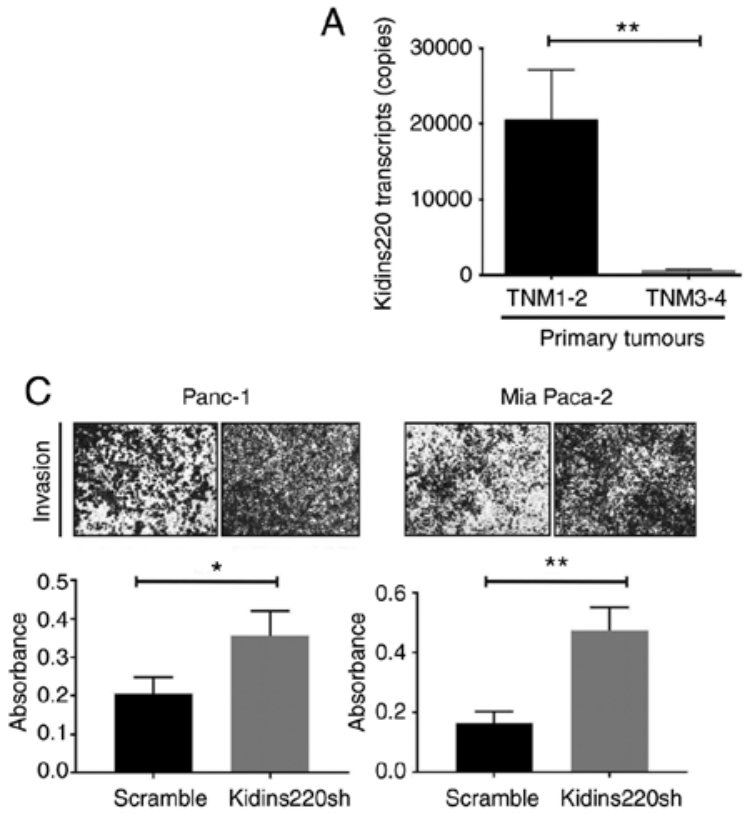

B

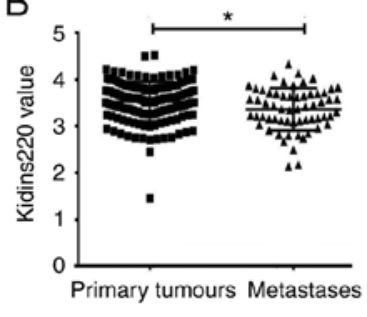

D
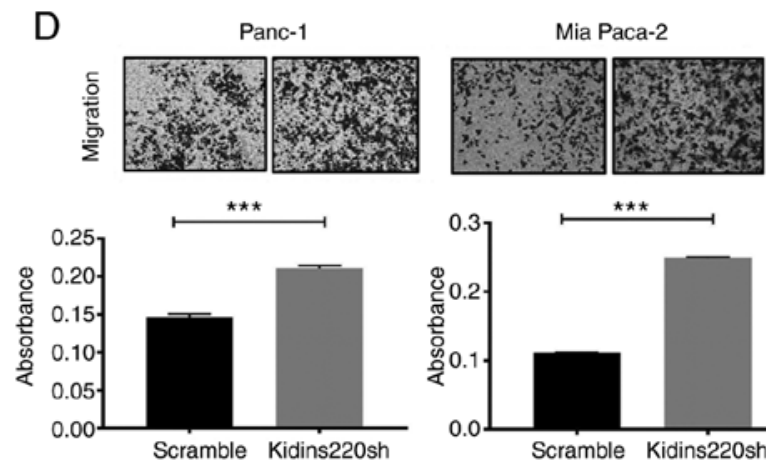

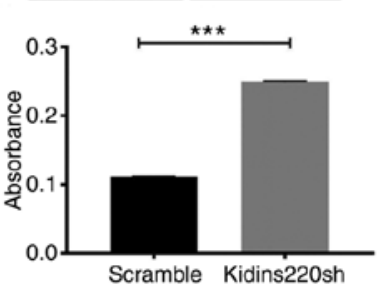

$\mathrm{E}$
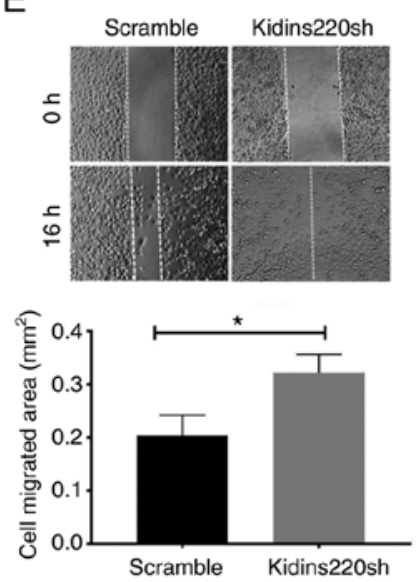

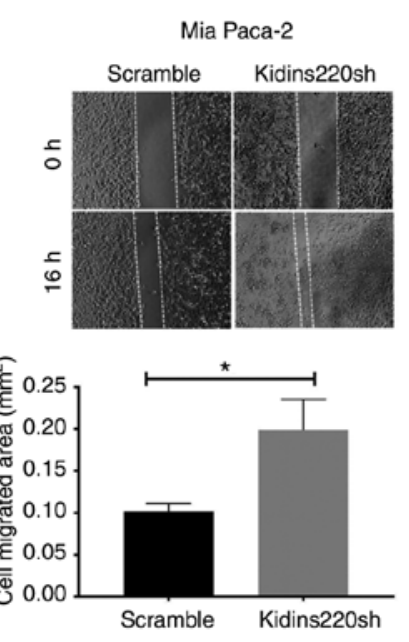

Figure 3. Kidins220 and disease progression of pancreatic cancer. (A) The levels of Kidins220 transcripts were determined in a cohort of pancreatic cancer using qPCR. Shown are Kidins220 transcript levels (mean \pm standard error of mean) in pancreatic tumors of early stages (TNM1 and TNM2) compared with advanced stages (TNM3 and TNM4) according to TNM staging. ${ }^{* *} \mathrm{P}<0.01$. (B) Kidins 220 transcript levels in distant metastases of pancreatic cancer compared with primary tumours were also analysed using a gene expression array data (GSE71729). * $\mathrm{P}<0.05$. (C) Knockdown of Kidins220 increases the invasive capacity of both PANC-1 and MIA PaCa-2 cell lines. Shown are Representative images of PANC-1 and MIA PaCa-2 cells after staining (upper panel) and the absorbance measured by dissolving the crystal violet stained invaded cells (bar graph). ${ }^{* *} \mathrm{P}<0.01$. Three experiments were performed. Error bars represent standard deviation. (D) Influence of Kidins220 knockdown on the migration of PANC-1 cells. Migration of PANC-1 and MIA PaCa-2 cells was determined using a Transwell migration assay, representative images of migrated cells are shown above the bar graph. ${ }^{* * *} \mathrm{P}<0.001,{ }^{* *} \mathrm{P}<0.01$. Error bars are standard deviation. (E) Effects of Kidins220 on cell migration examined by wound healing assay. Migration of PANC-1 and MIA PaCa-2 cancer cell lines was assayed by EVOS. Images were captured automatically at 0 and $16 \mathrm{~h}$ (magnification, x100). Shown are rrepresentative images of migrated PANC-1 and MIA PaCa-2 cells at 0 and $16 \mathrm{~h}$ (upper panel) and the migrated area was measured by calculating remaining gap size from the initial gap size. ${ }^{*}<<0.05$. ( $\left.\mathrm{F}\right) \mathrm{The}$ impact of Kidins 220 knockdown on peritoneal metastasis of PANC-1 cells in a mouse peritoneal metastasis model. Shown are tumour burden of the peritoneal metastasis nodules developed in each mouse. The tumor burden was determined based on the total tumor volume $\left(\mathrm{mm}^{3}\right)$ of each mouse against the corresponding body weight. Each group had six mice. ${ }^{*} \mathrm{P}<0.05$.

Loss of Kidins220 is accompanied with an enhanced epithelial mesenchymal transition (EMT) through EGFR. To determine whether Kidins220 affects EGFR-induced EMT in pancreatic cancer cells, the expression of EMT markers E-cadherin and Snail were detected using RT-PCR. Downregulation of E-cadherin and upregulation of Snail were observed in the PANC-1 ${ }^{\text {kidins220sh }}$ cells. E-cadherin was undetectable in the MIA PaCa-2 cells, but the expression of snail was increased in the MIA PaCa-2 $2^{\text {Kidins220sh }}$ cells (Fig. 6A), and the corresponding qPCR result for both cell lines is presented in Fig. 6C. Consistent changes were also observed in the protein levels of these EMT markers in those cell lines as a result of Kidins 220 knockdown (Fig. 6B). Targeting EGFR using gefitinib reversed the changes of E-cadherin and Snail in the PANC-1 $1^{\text {Kidins220sh }}$ cells, while a similar impact was observed for gefitinib in the MIA PaCa-2 cells on their expression of Snail (Fig. 6D and E). Another Kidins220 shRNA (CGAGTATTCAAGACTGAAGAT) exhibited similar impact on the EGFR and EMT in PANC-1 cells following the knockdown of Kidins220 (Fig. S1). 

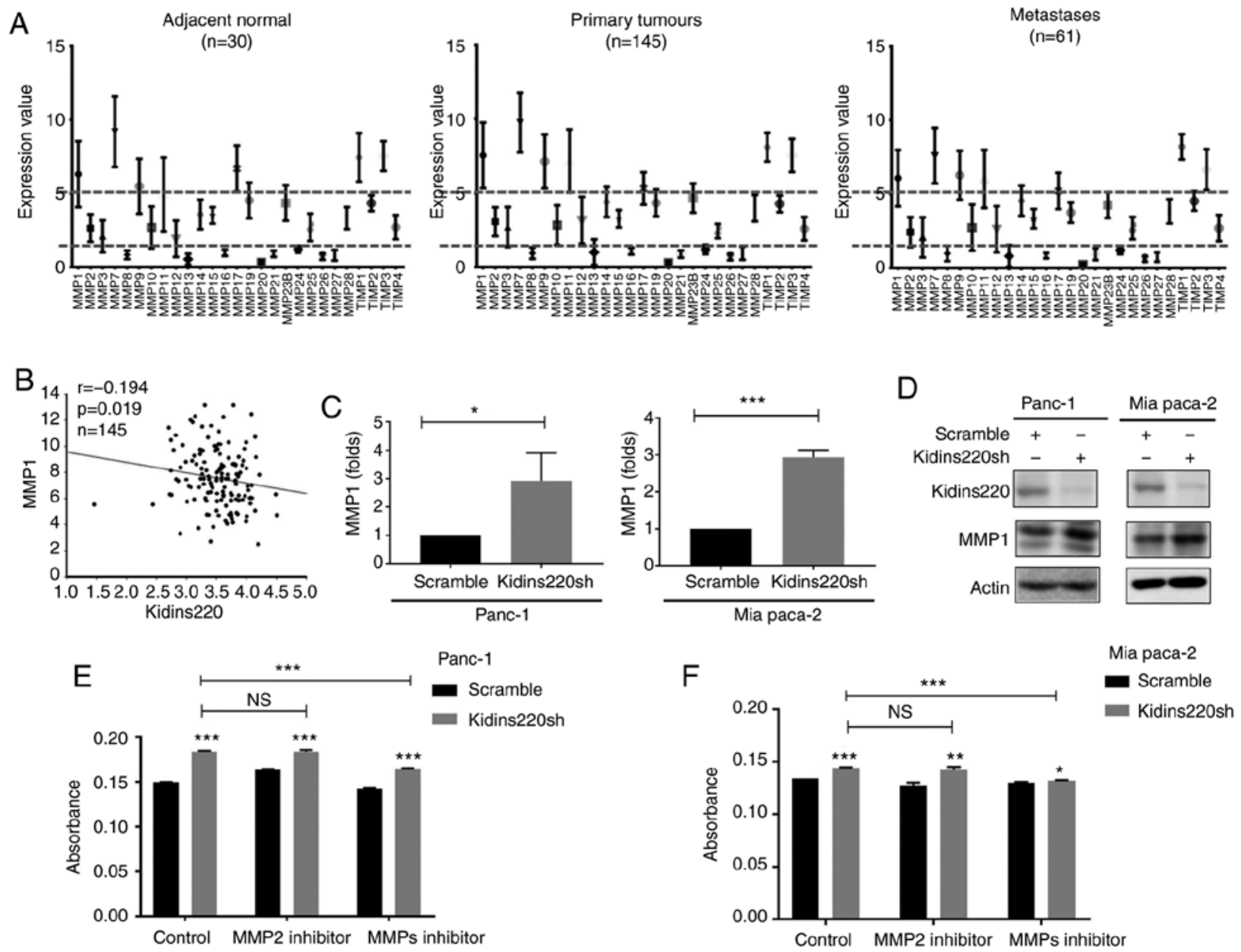

Figure 4. Increased pancreatic cancer cell invasion was regulated by activating ERK/MMP1 signalling. (A) Expression of MMPs transcripts in pancreatic primary tumours, metastatic tumours and adjacent normal pancreatic tissues (GSE71729). (B) Spearman correlation test was performed to test the correlation of Kidins220 and MMP1 $(\mathrm{P}=0.019)$. (C) Increased expression of MMP 1 in mRNA level with knockdown of Kidins220 was examined by QPCR in PANC-1 and MIA PaCa-2 cancer cell lines. (D) Western blot was performed to detect the expression of MMP1 in Kidins 220 knockdown PANC-1 and MIA PaCa-2 cancer cell lines. Cell invasion assay was conducted on PANC-1 (E) and MIA PaCa-2 (F) cancer cell lines treated with MMP2 inhibitor $12 \mathrm{nM}$ and MMPs broad spectrum inhibitor specific to MMP1 at $5 \mathrm{nM}$. One-way ANOVA (Bonferroni t-test) was employed for the statistical comparisons. ${ }^{* * * *} \mathrm{P}<0.001,{ }^{* * *} \mathrm{P}<0.01,{ }^{*} \mathrm{P}<0.05$.

Constitutive activity of both EGFR and NFkB are frequently observed in a variety of solid tumors as detailed in a previous review (10). Given that EGFR is known to be involved in the activation of $\mathrm{NF} \mathrm{B}$ (and the subsequent potential cellular effects in solid tumours) we determined the expression of $\mathrm{NF} \kappa \mathrm{B}$ in the pancreatic cancer cell lines with Kidins220 knockdown. Elevated levels of both $\mathrm{NF} \kappa \mathrm{B}$ transcripts and protein were seen in both PANC-1 ${ }^{\text {Kidins220sh }}$ and MIA PaCa- $2^{\text {kidins220sh }}$ cell lines compared to control. Corresponding increased nuclear $\mathrm{NF \kappa B}$ was also seen in these cell lines (Fig. 6F and G).

\section{Discussion}

Kidins220 is overexpressed in both melanoma and neuroblastoma, and associated with disease progression $(4,11,12)$. NGF can promote invasiveness of pancreatic cancer cells through upregulation of MMP2 (13). This is supported by a later study of NGF in pancreatic cancer cell lines in which NGF promoted proliferation and invasion of pancreatic cancer cells to various levels being associated with their differential expression of TrKA (14). BNDF and NT3 can promote invasiveness of pancreatic cancer cells at a low concentration while an inhibitory effect was evident at a higher concentration (100 ng/ml) (15). Although subsequent in vivo studies demonstrated a therapeutic potential of targeting Trks with a tyrosine kinase inhibitor CEP-701 for pancreatic cancer (16), little anticancer efficacy was evident in the relevant clinical trials (17). A cocktail of neutralising antibodies against NTs (NGF, BDNF, NT3 and NT4/5) exhibited an inhibitory effect on the in vivo growth of prostate cancer cells (PC-3) and pancreatic cancer cells (ASPC) (18). Trk receptors have been shown as differentially expressed genes in pancreatic cancer upon chemoradiotherapy, but no obvious effect was evident for targeting Trks using an inhibitor (AstraZeneca 1332) in the in vivo experiment (19). Findings of a previous study suggest that TrkA-expressing neuroendocrine tumors of stomach and pancreas may benefit from Trk target therapy (20). The NGF/Trk pathway is also involved in the stress-accelerated development of $\mathrm{Kras}^{\mathrm{G} 12 \mathrm{D}}$ driven PDAC, as indicated in a murine model (G12D) (21). However, TrkB is also considered a protective factor in anoikis for cancer cells particularly during their spread (22) which is yet to be fully investigated in the pancreatic cancer. Protein kinase D is a group of serine/threonine protein kinases comprising of three isoforms, PKD1, 
A
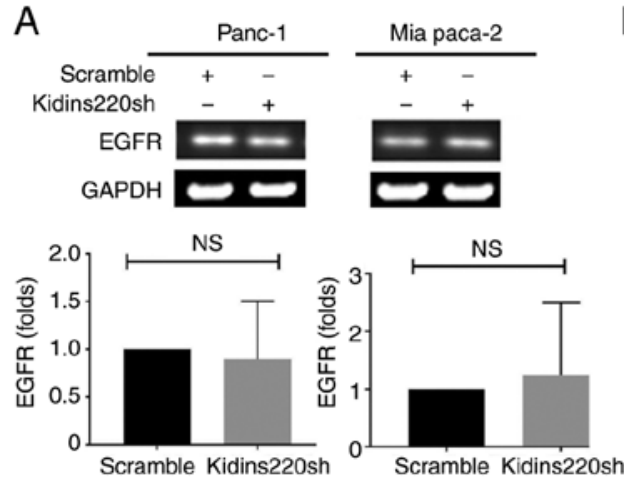

B

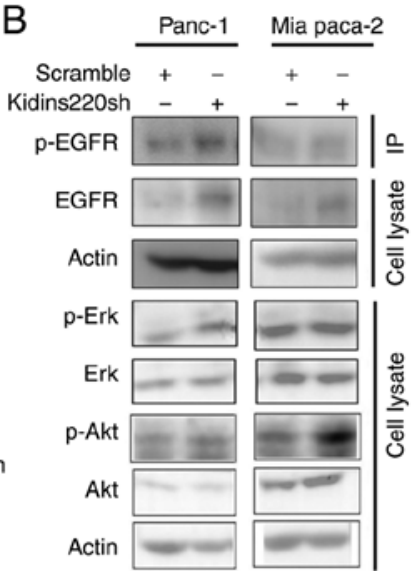

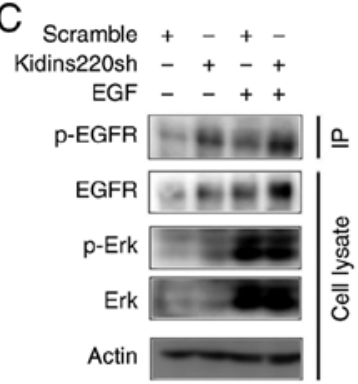
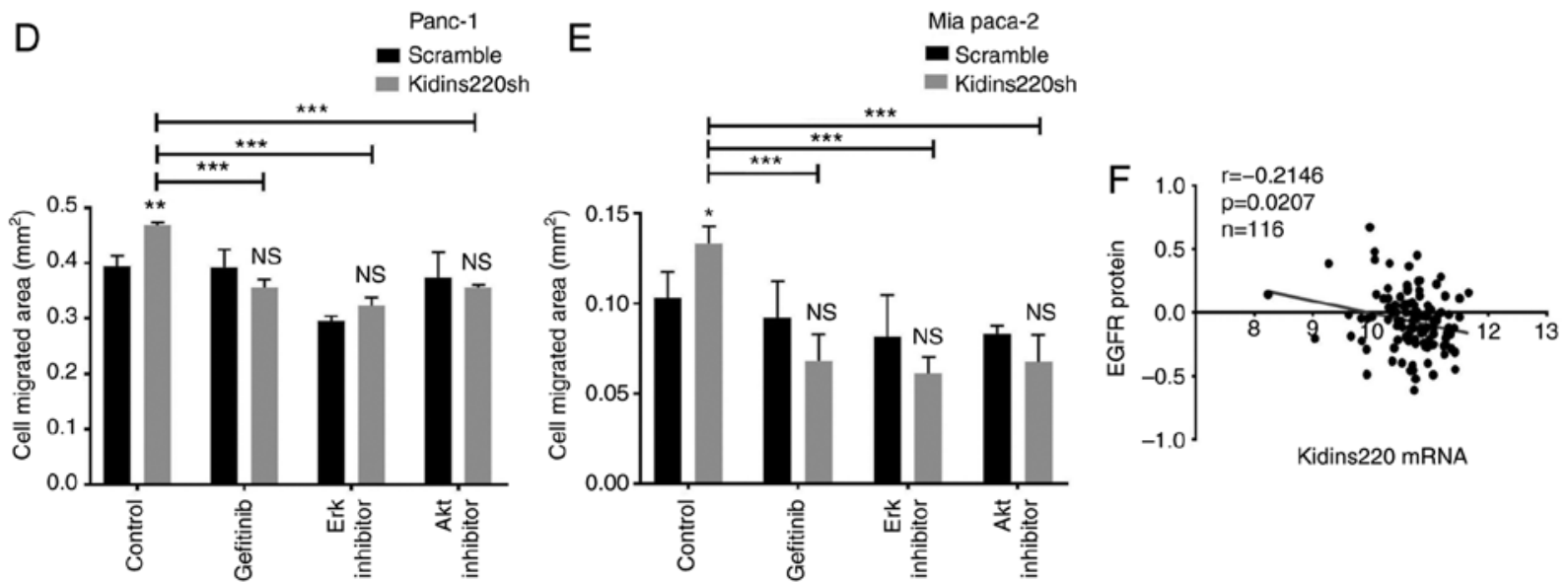

Figure 5. Kidins220 regulates the migration of pancreatic cancer cells through EGFR, ERK and AKT signalling pathway. (A) EGFR transcripts expressed by both PANC-1 and MIA PaCa-2 were determined using conventional RT-PCR and qPCR. NS represent no statistics significance. (B) The expression of total protein and tyrosine phosphorylation of EGFR were determined using immunoprecipitation and western blot analysis. Activation of ERK and AKT in Kidins220 knockdown cell lines was determined using western blot analysis. (C) The correlation of Kidins220 and EGF-induced EGFR and ERK activation in PANC-1 cancer cell lines. PANC-1 scramble and Kidins220 knockdown cells were serum-starved for $1 \mathrm{~h}$ before stimulation with vehicle control (-) and rhEGF (200 ng/ml) for $5 \mathrm{~min}$. Wound healing assay was performed to assess the effect of EGFR inhibitor, ERK inhibitor and AKT inhibitor in suppressing cell migration in PANC-1 (D) and Mia paca-2 cells (E). PANC-1 and MIA PaCa-2 cells were treated with 1 uM EGFR, ERK and AKT inhibitors for $16 \mathrm{~h}$ and the migrated area were measured by calculating remaining gap size from the initial gap size. One-way ANOVA (Bonferroni t-test) was employed for the statistical comparisons. ${ }^{* * *} \mathrm{P}<0.001,{ }^{* * *} \mathrm{P}<0.01,{ }^{*} \mathrm{P}<0.05$. (F) Correlation between EGFR protein and Kidins 220 mRNA in the TCGA pancreatic cancer cohort was analysed using the Spearman test.

PKD2 and PKD3 in mammals. In comparison with PKD2 and PKD3, PKD1 is more actively engaged with the tumorigenesis associated with TGF $\alpha$-induced acinar-to-ductal metaplasia (ADM) and Kras mutation (23). PKD1 is involved in the regulation of proliferation, survival and invasion of pancreatic cancer cells particularly when they lose their anchorage (24). Moreover, PDK1 can promote tumor-associated angiogenesis through upregulation of VEGF (23). PKD2 can also enhance the invasion of pancreatic cancer cells via the regulation of MMP7 and MMP9 (25). PKD inhibitors have been extensively tested for their anti-cancer potential in vitro and in vivo (26-28) which are yet to be examined in clinical trials. However, the development of PKD target therapy encounters a great challenge due to the low bioavailability and off-target effect. In contrast to the positive role played by the NTs, Trks and PKDs, our study found a significantly reduced expression of Kidins220 in pancreatic cancer, which is associated with poorer overall survival. It suggests that Kidins 220 as a downstream substrate of these molecules plays a different role in pancreatic cancers. This should be considered for the personalised disease management when these molecules are targeted. At present, little is known concerning the regulation of Kidins 220 compared with the understanding of its biological functions. Previous findings suggest that reduced miR-4638-5p led to an increased expression of Kidins220 in prostate cancer (6). Seven miRs were predicted be able to target Kidins 220 using the miRTarbase at the Enrichr platform (29). miR-4638-5p is the second among the seven miRs according to the combined score (Table SIII). However, miR-4638-5p was undetectable in the TCGA pancreatic cancer cohort. We analysed the correlation between the predicted miRs and Kidins 220 in the TCGA cohort. Spearman tests showed that miR-16-5p was inversely correlated with Kidins 220 while a positive correlation revealed between miR-7b-5p and Kidins220 (Table SIII). The possible regulation of Kidins 220 by these putative miRs is yet to be fully investigated by examining their expression in pancreatic cancer and specificity of targeting Kidins 220 .

The formation and metastasis of pancreatic cancer undergoes a multistep process from pancreatic intraepithelial 
A

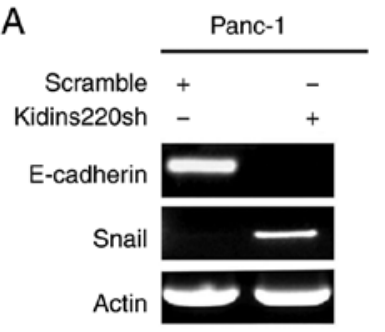

C

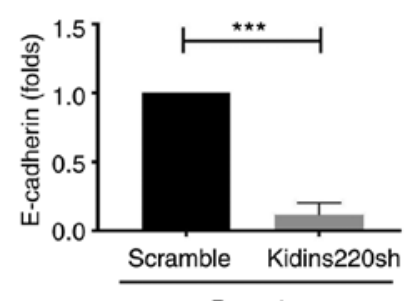

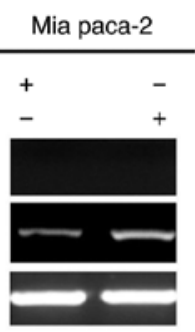

B

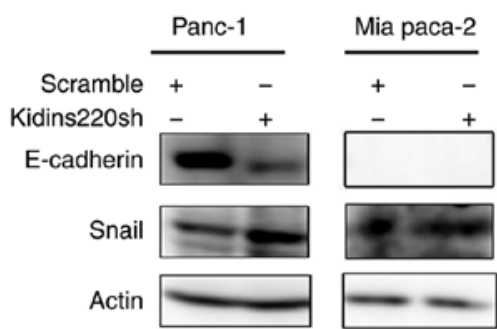

Panc-1
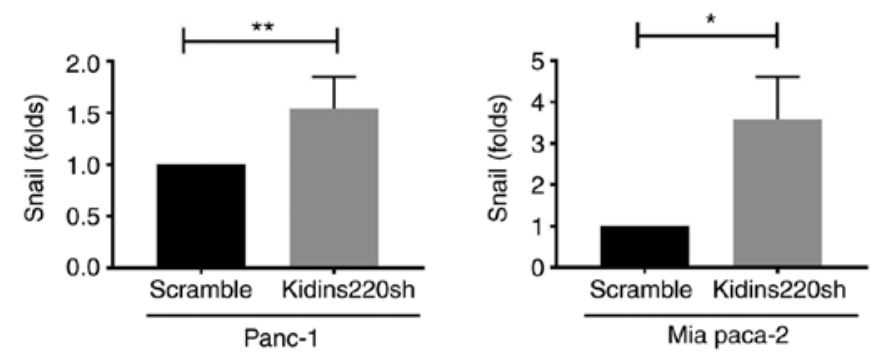

$\mathrm{F}$

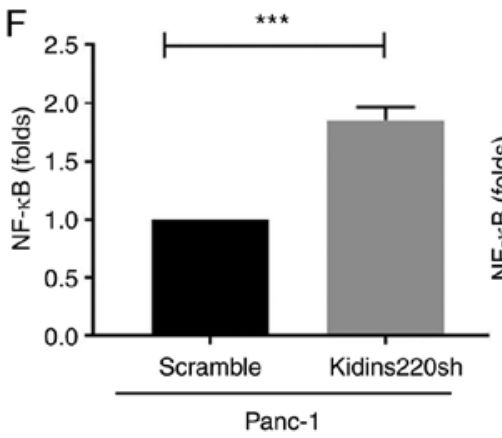

Panc-1
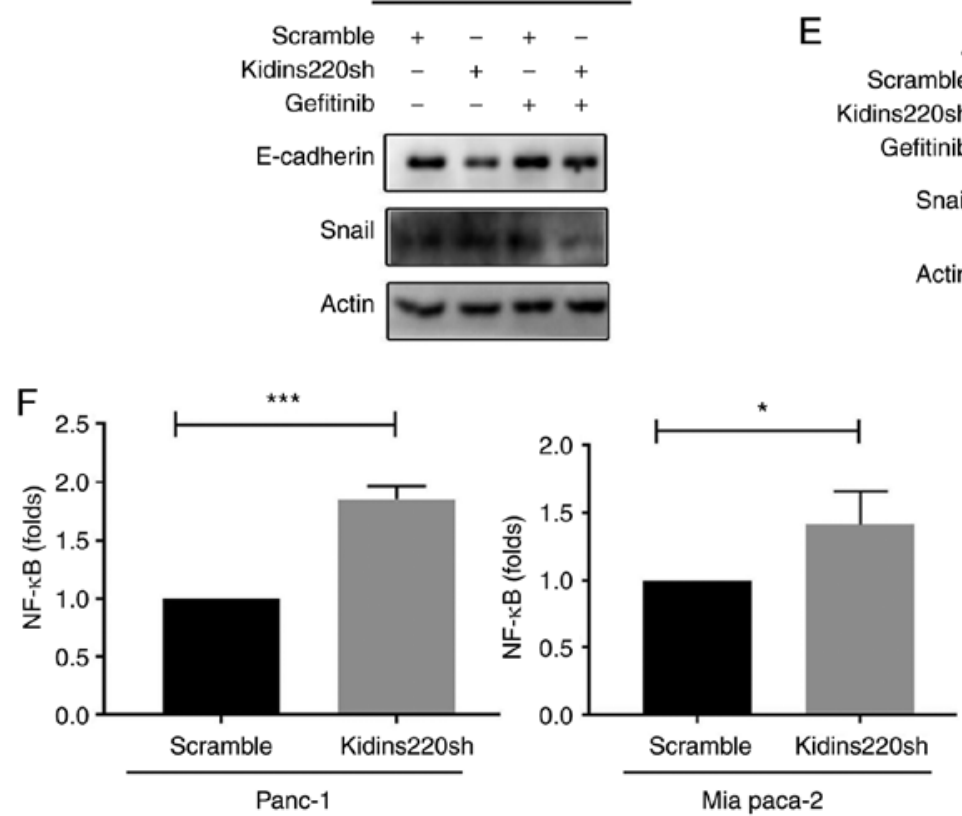

$\mathrm{E}$
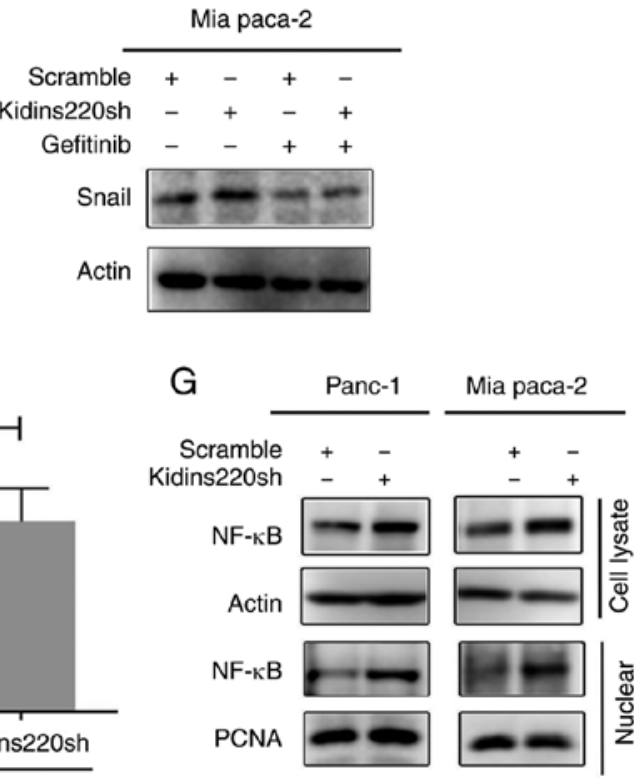

Figure 6. Kidins220 regulates the migration of pancreatic cancer cells through by EMT through EGFR and NF- $\mathrm{B}$ signalling pathway. (A) Expression of EMT markers E-cadherin and Snail at mRNA level was examined using RT-PCR. (B) Corresponding protein expression of these EMT markers was determined using western blot analysis. (C) The expression of EMT markers E-cadherin and snail was examined using QPCR at mRNA level. Western blotting was performed to detect the altered expression of EMT markers in the PANC-1 (D) and MIA PaCa-2 (E) cell lines treated with $1 \mu \mathrm{M}$ gefitinib. (F) NF- $\kappa \mathrm{B}$ expression was determined

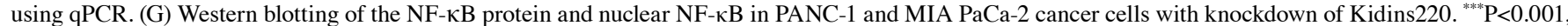
${ }^{* *} \mathrm{P}<0.01,{ }^{*} \mathrm{P}<0.05$.

neoplasia (PanIN) lesions to invasive carcinomas (30,31). Based on the analysis of a gene expression array data (GSE71729), the reduction of Kidins220 expression in invasive cancer originating in IPMN appeared to be significant compared with normal pancreas. Furthermore, according to IHC staining, there was a significant decrease of Kidins 220 expression in the malignant tumors compared with normal pancreas, hyperplasia or inflammation of the pancreas, and the benign tumors. Overexpression of Kidins 220 was able to protect cells from stress-induced apoptosis, while melanoma cells with Kidins 220 knockdown had a decrease in anchorage-independent growth in soft agar and an extended cell death following UVB-induced apoptosis (4). Similar to the findings in melanoma, a study of Kidins 220 in neuroblastoma also showed a positive role played by this molecule in the regulation of cell proliferation. Knockdown of Kidins 220 in neuroblastoma cells induced a decrease of proliferation through inhibition of the cell cycle in which an arrest at G1 phase was observed. The inhibitory effect on cell cycle was accompanied with decreased expression of cyclin D1 and cyclin-dependent kinase 4 (CDK4) and inhibition of hyperphosphorylated $\mathrm{pRb}$ to which an upregulation of p21 may contribute (11). In the present study, we found an enhanced tumorigenic capacity in the pancreatic cancer cells following the knockdown of Kidins 220 in an in vitro 3D tumor spheroid experimental model although its influence on the proliferation of pancreatic cancer cells appeared to be much less in the 2D proliferation tests. Knockdown of Kidins 220 also increased the colony numbers of pancreatic cancer cells and 
facilitated tumor growth in vivo. The impact on in vivo tumor growth observed in the xenograft model was more likely as a result from its regulation of both proliferation and motility of the pancreatic cancer cells in which invasion appeared to be predominately affected. This suggests that the downregulation of Kidins 220 may occur early during the tumorigenesis of pancreatic cancer. Furthermore, the reduced expression of Kidins220 in pancreatic cancer was associated with shorter overall survival, suggesting Kidins220 as a potential biomarker for the evaluation of prognosis of pancreatic cancer.

Kidins 220 may also play an important role in regulating the metastases of pancreatic cancer. The analysis of Kidins 220 transcript levels in the cohort of pancreatic cancer tissue samples showed more advanced pancreatic tumors (TNM3 and TNM4) had lower expression of Kidins220 compared with those of early stages (TNM1 and TNM2). In melanoma, Kidins 220 knockdown reduced migratory and invasive abilities of melanoma cells in vitro and in vivo (12). Our experiments showed that knockdown of Kidins220 in pancreatic cell lines resulted in an increase of cell migration and invasion. This is consistent with a reduced expression of Kidins220 observed in more advanced diseases, including both local invasion and spread to distant sites. Furthermore, knockdown of Kidins 220 also promoted peritoneal metastasis of pancreatic cancer cells in a murine peritoneal metastatic model. It suggests that the reduced expression of Kidins 220 in primary tumors conceives that pancreatic cancer cells are a more invasive phenotype for local invasion, dissemination and subsequent colonization at metastatic sites.

In pancreatic cancer, the expression pattern of EGF and its receptor has been studied for several years. Overexpression of EGFR has been indicated in pancreatic cancer and may be related to disease progression and poor survival of pancreatic cancer patients (32). Positive co-expression of EGF and EGFR was significantly associated with the poor prognosis of invasive ductal carcinoma of the pancreas. Patients with a negative expression of EGF and its receptor also had a 17.2 month median survival compared with the 9.7 month median survival in patients with positive expression of EGF and EGFR (33). In PDAC, EGFR expression of 30.4 to $61.8 \%$ has been reported (33). EGFR expression was related to increased invasiveness and poor prognosis. Park et al identified increased EGFR expression, rising from PanIN to PDAC, which indicated its potential role in the development of PDAC at an early stage (34). These EGFR aberrations contribute to an overactivation of pro-oncogenic signalling pathways such as the RAS-RAF-MEK-ERK MAPK and AKT-PI3K-mTOR pathways, which activate many cellular functions required by cancer cells, including proliferation, migration and invasion. The RAS-RAF-MEK-ERK MAPK pathway in particular may be the most important pathway in mediating the biological response of EGFR (35). These pathways have both been implicated in the development of pancreatic cancer and are also being evaluated as therapeutic targets $(36,37)$.

In the present study, we found knockdown of Kidins 220 increased the phosphorylation of EGFR and total EGFR in pancreatic cancer cell lines, without a notable change of Kidins220 transcripts. An inverse correlation between the Kidins220 transcripts and EGFR protein was also evident in the TCGA pancreatic cancer cohort. It suggests that either a post-transcriptional or post-translational regulation of EGFR occurred in the pancreatic cancer cells when Kidins 220 was knocked down albeit the exact mechanism is yet to be investigated. Previous findings showed that Kidins220 regulates the tumor formation of melanoma through MEK/ERK signalling pathway (12). Downregulation of Kidins220 resulted in the attenuation of NGF-induced, but not BDNF-induced MAPK signalling in neuroblastoma cells (38). Kidins220 was also involved in the angiogenesis of castration-resistant prostate cancer through the activity of VEGF and the PI3K/AKT pathway, which is regulated by miR-4638-5p (6). In the present study, corresponding changes of ERK and AKT were identified in the Kidins 220 knockdown cell lines, by which knockdown of Kidins220 increased phosphorylation of ERK and AKT. The altered expression pattern of ERK was also further enhanced by treatment with EGF. Furthermore, the involvement of EGFR/ERK and/or AKT in the promotion of cell migration observed in Kidins 220 knockdown cells was elucidated using ERK, AKT, and EGFR small inhibitors. Moreover, EGFR and Kras mutations may confer enhanced EGFR signalling and a consequent challenge to EGFR target therapy $(39,40)$. The role played by Kidins 220 in the EGFR and Kras mutation-related activation of EGFR signalling is yet to be fully elucidated.

Cellular migration is an important part of the multistep process required for cancer metastasis that also includes proliferation, adhesion and invasion. Epithelial-mesenchymal transition (EMT) and MMPs are two important factors in the regulation of cancer cell migration and invasion. EMT enables cancer cells to disseminate from a primary tumor to a distant site and finally develop a secondary tumor (41). It occurs when tumor cells lose their epithelial features such as loss of polarity, and gain mesenchymal phenotype, acquiring the capability of motility and invasion $(42,43)$. E-cadherin is considered a determinant molecule that maintains cell-cell adhesion and cell polarity (43), as such downregulation of E-cadherin is a critical event in EMT, found to be caused by the overexpression of several different EMT-inducing factors, such as Snail, a zinc-finger transcription repressor, and transcriptional repressor of E-cadherin expression. In pancreatic cancer cells, Snail exhibited a higher level of expression together with a reduced expression of E-cadherin in poorly differentiated cell lines compared with their expression in moderately differentiated cell lines (44). The present findings indicated that knockdown of Kidins 220 decreased the expression of E-cadherin in PANC-1 cells and increased the protein expression of Snail in PANC-1 and MIA PaCa- 2 cells. When treating PANC-1 cells with gefitinib, the Kidins 220 knockdown cells started to recover the expression of E-cadherin, and the expression of Snail was completely inhibited with gefitinib in PANC-1 cells. Our study also indicated an increased expression of NF- $\kappa \mathrm{B}$ at the transcription and protein level in Kidins 220 knockdown pancreatic cells. Inhibition of the NF- $\kappa \mathrm{B}$ pathway leads to deregulation of epithelial-mesenchymal transition and neural invasion in pancreatic cancer (45). However, its role in the regulation of EMT underlying the expression of Kidins 220 needs to be further investigated.

The proteolytic activity of MMPs is required for a cancer cell to degrade extracellular matrix during local expansion and intravasation at nearby blood vessels, and additionally 
extravasation and invasion at a distant location. High MMP1 expression is associated poor prognosis in patients with breast cancer including disease-free and overall survival (20), but its role in pancreatic cancer and any functional relation to Kidins 220 is unknown.

Since knockdown of Kidins 220 resulted in the increased invasive capability of pancreatic cancer cells, we examined whether MMPs, which are able to degrade the extracellular matrix contributed to the observed tumor cell invasion (46). MMPs, particularly MMP-2 and, to a lesser extent, MMP-9, modulate the pathogenesis of pancreatic cancer $(47,48)$. In the current study, we found a positive correlation of Kidins 220 and MMP1. Knockdown of Kidins220 promoted the transcript level of MMP1 in PANC-1 and MIA PaCa-2 cells. Moreover, an increased expression of MMP1 was also detected at the protein level. In invasive melanoma, overexpression of MMP1 is regulated by the ERK signalling pathway (49). The increased expression of MMP1 in MIA PaCa-2 Kidins 220 knockdown cells can be inhibited when cells were treated with ERK Inhibitor for $2 \mathrm{~h}$. Interestingly, MMP2 inhibitor cannot prevent the increased cell invasion seen with knockdown of Kidins220; however, an MMP broad spectrum inhibitor at a specific MMP1-inhibiting concentration was able to reduce the invasiveness of Kidins 220 knockdown cells but to different levels. Kidins 220 knockdown-promoted invasion of MIA PaCa-2 appears to be more dependent on the MMP1 while PANC1 appears to less responsive to the inhibitor (Marimastat). It suggests that other MMPs or pathways may be involved which is yet to be elucidated.

In summary, a reduced expression of Kidins 220 was observed in pancreatic cancer, and this reduced expression is associated with disease progression, distant metastases and poor prognosis. The reduced expression of Kidins 220 in pancreatic cancer cells is associated with enhanced tumorigenic and metastatic traits, through upregulation of EGFR and MMP1, and promotion of EMT. It suggests that Kidins 220 is a putative marker for a more effective and specific therapy in the personalised disease management by targeting EGFR and its downstream signalling. This requires further evaluation by employing both in vivo models and a specifically designed clinical study.

There remain questions of further interest that require additional studies for instance, the molecular mechanism utilised by the Kidins 220 to regulate the protein level of EGFR, in which protein degradation cascades may be affected. More importantly, the exact implication of the reduced expression of Kidins220 in EGFR-positive pancreatic cancer should be elucidated by considering other HER family members, K-Ras and EGFR mutation, as this may have significant implications in selecting more personalised therapeutic regimes for pancreatic cancer patients.

\section{Acknowledgements}

The authors would like to thank both Peking University and Cardiff University for their kind support to this collaborative research. We also extend thanks to Dr Andrew Sanders, Ms. Catherine Zabkiewicz, Dr Jun Cai and Dr Lee Campbell for their help on the proof reading, constructive comments and discussions.

\section{Funding}

Not applicable.

\section{Availability of data and materials}

All data presented within the article are available upon request from the corresponding author.

\section{Authors' contributions}

LY designed the study. SC, ZS, PHS, XG and LY performed the in vitro experiments. $\mathrm{SC}, \mathrm{ZS}, \mathrm{CL}, \mathrm{FS}$ and $\mathrm{LY}$ conducted the in vivo experiments. XG, KJ, XT, JJ and $\mathrm{CH}$ collected the pancreatic tissue samples and carried out RNA isolation at the Beijing Cancer Hospital. PG and BA conducted the evaluation of TMA and data analysis. SC, ZS, FS, BAS, SH, WGJ and LY were involved in data analysis and preparation of the manuscript. All authors read and approved the manuscript.

\section{Ethics approval and consent to participate}

The pancreatic cancer tumors together with paired adjacent normal pancreatic tissues were collected at the Peking University Cancer Hospital by complying with the regulations and approved procedures. All protocols and procedures were reviewed and approved Peking University Cancer Hospital Research Ethics Committee.

\section{Patient consent for publication}

Not applicable.

\section{Competing interests}

The authors declare no conflict of interest.

\section{References}

1. Scholz-Starke J and Cesca F: Stepping out of the shade: Control of neuronal activity by the scaffold protein Kidins220/ARMS. Front Cell Neurosci 10: 68, 2016.

2. Neubrand VE, Cesca F, Benfenati $F$ and Schiavo G: Kidins220/ARMS as a functional mediator of multiple receptor signalling pathways. J Cell Sci 125: 1845-1854, 2012.

3. Cai S, Cai J, Jiang WG and Ye L: Kidins220 and tumour development: Insights into a complexity of cross-talk among signalling pathways (review). Int J Mol Med 40: 965-971, 2017.

4. Liao YH, Hsu SM and Huang PH: ARMS depletion facilitates UV irradiation induced apoptotic cell death in melanoma. Cancer Res 67: 11547-11556, 2007.

5. Rogers DA and Schor NF: Kidins220/ARMS depletion is associated with the neural-to Schwann-like transition in a human neuroblastoma cell line model. Exp Cell Res 319: 660-669, 2013.

6. Wang Y, Shao N, Mao X, Zhu M, Fan W, Shen Z, Xiao R, Wang C, Bao W, Xu X, et al: MiR-4638-5p inhibits castration resistance of prostate cancer through repressing Kidins220 expression and PI3K/AKT pathway activity. Oncotarget 7: 47444-47464, 2016.

7. Sobin LH, Gospodarowicz MK and Wittekind C (eds): TNM classification of malignant tumours. 7th edition. Wiley-Blackwell, Chichester, West Sussex, pp132-135, 2009.

8. Livak KJ and Schmittgen TD: Analysis of relative gene expression data using real-time quantitative PCR and the 2(-Delta Delta C(T)) method. Methods 25: 402-408, 2001.

9. Hiraoka N, Yamazaki-Itoh R, Ino Y, Mizuguchi Y, Yamada T, Hirohashi S and Kanai Y: CXCL17 and ICAM2 are associated with a potential anti-tumor immune response in early intraepithelial stages of human pancreatic carcinogenesis. Gastroenterology 140: 310-321, 2011. 
10. Shostak K and Chariot A: EGFR and NF-кB: Partners in cancer Trends Mol Med 21: 385-393, 2015.

11. Jung H, Shin JH, Park YS and Chang MS: Ankyrin repeat-rich membrane spanning (ARMS)/Kidins220 scaffold protein regulates neuroblastoma cell proliferation through p21. Mol Cells 37: 881-887, 2014

12. Liao YH, Hsu SM, Yang HL, Tsai MS and Huang PH: Upregulated ankyrin repeat-rich membrane spanning protein contributes to tumour progression in cutaneous melanoma. Br J Cancer 104: 982-988, 2011

13. Okada Y, Eibl G, Guha S, Duffy JP, Reber HA and Hines OJ: Nerve growth factor stimulates MMP-2 expression and activity and increases invasion by human pancreatic cancer cells. Clin Exp Metastasis 21: 285-292, 2004.

14. Diao DM, Song YC, Hou N, Xu HF, Wang JG and Dang CX: Responses of pancreatic cancer cells to stimulations by nerve growth factor and the role of Trk-A expression. Nan Fang Yi Ke Da Xue Xue Bao 32: 296-300, 2012 (In Chinese).

15. Miknyoczki SJ, Lang D, Huang L, Klein-Szanto AJ, Dionne CA and Ruggeri BA: Neurotrophins and Trk receptors in human pancreatic ductal adenocarcinoma: Expression patterns and effects on in vitro invasive behavior. Int J Cancer 81: 417-427, 1999.

16. Miknyoczki SJ, Chang H, Klein-Szanto A, Dionne CA and Ruggeri BA: The Trk tyrosine kinase inhibitor CEP-701 (KT-5555) exhibits significant antitumor efficacy in preclinical xenograft models of human pancreatic ductal adenocarcinoma. Clin Cancer Res 5: 2205-2212, 1999.

17. Shabbir M and Stuart R: Lestaurtinib, a multitargeted tyrosine kinase inhibitor: From bench to bedside. Expert Opin Investig Drugs 19: 427-436, 2010

18. Miknyoczki SJ, Wan W, Chang H, Dobrzanski P, Ruggeri BA, Dionne CA and Buchkovich K: The neurotrophin-trk receptor axes are critical for the growth and progression of human prostatic carcinoma and pancreatic ductal adenocarcinoma xenografts in nude mice. Clin Cancer Res 8: 1924-1931, 2002.

19. Johnson MD, Stone B, Thibodeau BJ, Baschnagel AM, Galoforo S, Fortier LE, Ketelsen B, Ahmed S, Kelley Z, Hana A, et al: The significance of Trk receptors in pancreatic cancer. Tumour Biol 39: 1010428317692256, 2017.

20. Aristizabal Prada ET, Heinzle V, Knösel T, Nölting S, Spöttl G, Maurer J, Spitzweg C, Angele M, Schmidt N, Beuschlein F, et al: Tropomyosin receptor kinase: A novel target in screened neuroendocrine tumors. Endocr Relat Cancer 25: 547-560, 2018.

21. Renz BW, Takahashi R, Tanaka T, Macchini M, Hayakawa Y, Dantes Z, Maurer HC, Chen X, Jiang Z, Westphalen CB, et al: $\beta 2$ adrenergic-neurotrophin feedforward loop promotes pancreatic cancer. Cancer Cell 33: 75-90.e7, 2018.

22. Desmet CJ and Peeper DS: The neurotrophic receptor TrkB: A drug target in anti-cancer therapy? Cell Mol Life Sci 63: 755-759, 2006.

23. Liou GY, Döppler H, Braun UB, Panayiotou R, Scotti Buzhardt M, Radisky DC, Crawford HC, Fields AP, Murray NR Wang QJ, et al: Protein kinase D1 drives pancreatic acinar cell reprogramming and progression to intraepithelial neoplasia. Nat Commun 6: 6200, 2015.

24. Ochi N, Tanasanvimon S, Matsuo Y, Tong Z, Sung B, Aggarwal BB, Sinnett-Smith J, Rozengurt E and Guha S: Protein kinase D1 promotes anchorage-independent growth, invasion, and angiogenesis by human pancreatic cancer cells. J Cell Physiol 226 1074-1081, 2011

25. Wille C, Köhler C, Armacki M, Jamali A, Gössele U Pfizenmaier K, Seufferlein T and Eiseler T: Protein kinase D2 induces invasion of pancreatic cancer cells by regulating matrix metalloproteinases. Mol Biol Cell 25: 324-336, 2014.

26. Evans IM, Bagherzadeh A, Charles M, Raynham T, Ireson C, Boakes A, Kelland L and Zachary IC: Characterization of the biological effects of a novel protein kinase $\mathrm{D}$ inhibitor in endothelial cells. Biochem J 429: 565-572, 2010.

27. Harikumar KB, Kunnumakkara AB, Ochi N, Tong Z, Deorukhkar A, Sung B, Kelland L, Jamieson S, Sutherland R, Raynham T, et al: A novel small-molecule inhibitor of protein kinase D blocks pancreatic cancer growth in vitro and in vivo. Mol Cancer Ther 9: 1136-1146, 2010.

28. Li QQ, Hsu I, Sanford T, Railkar R, Balaji N, Sourbier C, Vocke C, Balaji KC and Agarwal PK: Protein kinase D inhibitor CRT0066101 suppresses bladder cancer growth in vitro and xenografts via blockade of the cell cycle at G2/M. Cell Mol Life Sci 75: 939-963, 2018
29. Kuleshov MV, Jones MR, Rouillard AD, Fernandez NF, Duan Q, Wang Z, Koplev S, Jenkins SL, Jagodnik KM, Lachmann A, et al: Enrichr: A comprehensive gene set enrichment analysis web server 2016 update. Nucleic Acids Res 44: W90-W97, 2016.

30. Hidalgo M: Pancreatic cancer. N Engl J Med 362: 1605-1617, 2010.

31. Makohon-Moore A and Iacobuzio-Donahue CA: Pancreatic cancer biology and genetics from an evolutionary perspective. Nat Rev Cancer 16: 553-565, 2016.

32. Oliveira-Cunha M, Newman WG and Siriwardena AK Epidermal growth factor receptor in pancreatic cancer. Cancers (Basel) 3: 1513-1526, 2011.

33. Dong M, Nio Y, Guo KJ, Tamura K, Tian YL and Dong YT: Epidermal growth factor and its receptor as prognostic indicators in Chinese patients with pancreatic cancer. Anticancer Res 18: 4613-4619, 1998.

34. Park SJ, Gu MJ, Lee DS, Yun SS, Kim HJ and Choi JH: EGFR expression in pancreatic intraepithelial neoplasia and ductal adenocarcinoma. Int J Clin Exp Pathol 8: 8298-8304, 2015.

35. Wee $\mathrm{P}$ and Wang Z: Epidermal growth factor receptor cell proliferation signaling pathways. Cancers (Basel) 9: 52, 2017.

36. Roy SK, Srivastava RK and Shankar S: Inhibition of PI3K/AKT and MAPK/ERK pathways causes activation of FOXO transcription factor, leading to cell cycle arrest and apoptosis in pancreatic cancer. J Mol Signal 5: 10, 2010.

37. Williams TM, Flecha AR, Keller P, Ram A, Karnak D Galbán S, Galbán CJ, Ross BD, Lawrence TS, Rehemtulla A and Sebolt-Leopold J: Cotargeting MAPK and PI3K signaling with concurrent radiotherapy as a strategy for the treatment of pancreatic cancer. Mol Cancer Ther 11: 1193-1202, 2012.

38. Rogers DA and Schor NF: Kidins220/ARMS is expressed in neuroblastoma tumors and stabilizes neurotrophic signaling in a human neuroblastoma cell line. Pediatr Res 74: 517-524, 2013.

39. Kim ST, Lim DH, Jang KT, Lim T, Lee J, Choi YL, Jang HL, Yi JH, Baek KK, Park SH, et al: Impact of KRAS mutations on clinical outcomes in pancreatic cancer patients treated with first-line gemcitabine-based chemotherapy. Mol Cancer Ther 10: 1993-1999, 2011

40. Lee J, Jang KT, Ki CS, Lim T, Park YS, Lim HY, Choi DW, Kang WK, Park K and Park JO: Impact of epidermal growth factor receptor (EGFR) kinase mutations, EGFR gene amplifications, and KRAS mutations on survival of pancreatic adenocarcinoma. Cancer 109: 1561-1569, 2007.

41. Thiery JP: Epithelial-mesenchymal transitions in tumour progression. Nat Rev Cancer 2: 442-454, 2002.

42. Yeung KT and Yang J: Epithelial-mesenchymal transition in tumor metastasis. Mol Oncol 11: 28-39, 2017.

43. Thiery JP, Acloque H, Huang RY and Nieto MA: Epithelialmesenchymal transitions in development and disease. Cell 139: 871-890, 2009

44. Hotz B, Arndt M, Dullat S, Bhargava S, Buhr HJ and Hotz HG: Epithelial to mesenchymal transition: Expression of the regulators snail, slug, and twist in pancreatic cancer. Clin Cancer Res 13: 4769-4776, 2007.

45. Nomura A, Majumder K, Giri B, Dauer P, Dudeja V, Roy S, Banerjee S and Saluja AK: Inhibition of NF-kappa B pathway leads to deregulation of epithelial-mesenchymal transition and neural invasion in pancreatic cancer. Lab Invest 96: 1268-1278, 2016.

46. Gialeli C, Theocharis AD and Karamanos NK: Roles of matrix metalloproteinases in cancer progression and their pharmacological targeting. FEBS J 278: 16-27, 2011.

47. Koshiba T, Hosotani R, Wada M, Miyamoto Y, Fujimoto K, Lee JU, Doi R, Arii S and Imamura M: Involvement of matrix metalloproteinase-2 activity in invasion and metastasis of pancreatic carcinoma. Cancer 82: 642-650, 1998.

48. Bloomston M, Zervos EE and Rosemurgy AS II: Matrix metalloproteinases and their role in pancreatic cancer: A review of preclinical studies and clinical trials. Ann Surg Oncol 9: 668-674, 2002

49. Huntington JT, Shields JM, Der CJ, Wyatt CA, Benbow U, Slingluff CL Jr and Brinckerhoff CE: Overexpression of collagenase 1 (MMP-1) is mediated by the ERK pathway in invasive melanoma cells: role of BRAF mutation and fibroblast growth factor signaling. J Biol Chem 279: 33168-33176, 2004. 